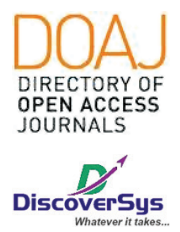

Published by DiscoverSys

\title{
Profil gangguan fungsi kognitif pada pasien pasca stroke iskemik di RSUP Sanglah Denpasar Bali, Indonesia periode 2019
}

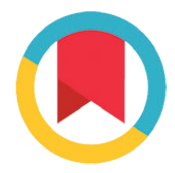

CrossMark

\author{
Bimo Adi Laksono, ${ }^{1 *}$ Ketut Widyastuti, ${ }^{2}$ Sri Yenni Trisnawati ${ }^{2}$
}

\section{ABSTRACT}

Background: Stroke is a disease that affects straightly to the brain. Stroke occured due to obstruction of blood vessel that contain bloodtransporting nutrients to the brain, which lead to impairment in brain function, as well as cognitive function. Because of unavailibility of data in Sanglah General Hospital, this research must be done. This study aims to determine the cognitive function profile of post ischemic stroke patient in Sanglah General Hospital based on 5 cognitive domains.

Methods: This study is an observational study, collecting data by cross sectional. Data sources were obtained from primary data in the form of interview and MoCA-Ina Test with data retrieval methods using totally sampling technique. The accessible population was patients post ichemic stroke in Sanglah General Hospital that is in a good awareness and fit for MoCA-Ina test.

Results: From 26 patients that are accessible, 21 patients were diagnosed with cognitive impairment, which the majority in 41-50 range of age with 9 patients, male with 14 patients, last education of Junior High School with 7 patients, and memory being a domain which is most impaired with mean of $55,38 \%$ score.

Conclusion: The most affected domain is after an ischemic stroke is memory and visuospacial function

Keywords: Cognitive function, post ischemic stroke patient, cognitive domains, MoCA-Ina.

Cite This Article: Laksono, B.A., Widyastuti, K., Trisnawati, S.Y. 2019. Profil gangguan fungsi kognitif pada pasien pasca stroke iskemik di RSUP Sanglah Denpasar Bali, Indonesia periode 2019. Intisari Sains Medis 10(3): 698-701. D0I: 10.15562/ism.v10i3.463

\section{ABSTRACT}

Latar Belakang: Stroke merupakan penyakit yang secara langsung menyerang otak. Penyakit stroke bermula dari pembuluh darah menuju otak tersumbat atau terhalang, sehingga menyebabkan otak kekurangan suplai darah yang membawa oksigen dan nutrien seperti glukosa dan menyebabkan otak mengalami penurunan fungsi kognitif. Oleh karena di RSUP Sanglah belum ada data yang valid mengenai profil fungsi kognitif pada pasien pasca stroke iskemik, dilakukanlah penelitian ini. Penelitian ini bertujuan untuk mengetahui profil fungsi kognitif pada pasien pasca stroke iskemik di RSUP Sanglah Denpasar berdasarkan kelima domain kognitif, yaitu atensi, bahasa, memori, visuospasial, dan fungsi eksekutif.

'Program Studi Pendidikan Dokter, Fakultas Kedokteran, Universitas Udayana, Bali-Indonesia

${ }^{2}$ Departemen/KSM, IImu Penyakit Saraf, Fakultas Kedokteran, Universitas Udayana-RSUP Sanglah Denpasar, Bali-Indonesia

${ }^{*}$ Correspondence to:

Bimo Adi Laksono, Program Studi Pendidikan Dokter, Fakultas

Kedokteran, Universitas Udayana, Bali-Indonesia

bimoadil69@gmail.com

Diterima: 28-03-2019

Disetujui: 11-04-2019

Diterbitkan: 01-12-2019
Metode: Penelitian ini merupakan penelitian observasional, pengumpulan data secara potong lintang. Sumber data diperoleh dari data primer berupa hasil wawancara pasien dan tes MoCA-Ina dengan
Kata Kunci: Fungsi kognitif, pasien pasca stroke iskemik, domain kognitif, MoCA-Ina.

\section{PENDAHULUAN}

Stroke merupakan penyakit yang secara langsung menyerang otak. Penyakit stroke bermula dari pembuluh darah menuju otak tersumbat atau terhalang, sehingga menyebabkan otak kekurangan suplai darah yang membawa oksigen dan nutrien metode pengambilan data menggunakan teknik sampling total. Pada penelitian ini, populasi terjangkau merupakan pasien pasca stroke iskemik yang rawat jalan di poli saraf RSUP Sanglah Denpasar Bali, dalam keadaan sadar, dan memenuhi syarat untuk menjalani tes MocA-Ina.

Hasil: Dari 26 pasien yang terinklusi, sebanyak 21 pasien mengalami gangguan fungsi kognitif $(80,8 \%)$, dengan mayoritas berada pada rentang usia 41-50 tahun dengan jumlah 9 pasien, berjenis kelamin laki-laki dengan jumlah 14 pasien, berpendidikan terakhir SMP dengan jumlah 7 pasien, dan domain yang paling menunjukkan adanya penurunan adalah memori dengan rata-rata skor $55,38 \%$.

Simpulan: Domain Kognitif yang paling terganggu pasca stroke iskemik adalah domain memori dan yang paling sedikit terganggu adalah visuospasial.

Cite Pasal Ini: Laksono, B.A., Widyastuti, K., Trisnawati, S.Y. 2019. Profil gangguan fungsi kognitif pada pasien pasca stroke iskemik di RSUP Sanglah Denpasar Bali, Indonesia periode 2019. Intisari Sains Medis 10(3): 698-701. D0I: 10.15562/ism.v10i3.463

seperti glukosa dan menyebabkan sel-sel otak mengalami penurunan fungsi (Jun Liang et al, 2010). Jenis stroke ada dua, yaitu iskemik dan hemoragik. ${ }^{1}$ Menurut World Health Organization (WHO), stroke merupakan penyakit yang 
menyebabkan kematian terbanyak di dunia nomor 3 setelah penyakit jantung dan kanker. $^{2}$

Fungsi kognitif adalah kemampuan intelektual untuk mendapat, mengolah, dan mengaplikasikan informasi yang tak berhubungan dengan nilai-nilai akademik. ${ }^{3}$ Kemampuan ini mencakup memori, problem solving, berbicara, belajar, dan merencanakan sesuatu.

Stroke iskemik adalah penyakit yang menyebabkan fungsi kerja otak menurun. Saat fungsi kerja otak menurun, kemampuan dan fungsi kognitif penderita pasti akan terpengaruh secara signifikan maupun tidak. Stroke iskemik adalah penyakit yang mematikan, namun semua pasien pasti memiliki harapan hidup. Masalahnya, dari seluruh pasien yang bertahan hidup, fungsi kognitif mereka belum tentu sama dengan sebelum terkena stroke. Jika stroke menyebabkan sel-sel otak tidak lagi berkerja optimal, gangguan kognitif pasti akan rentan terjadi. ${ }^{4}$

Menurut data, di Rumah Sakit Prof DR. R. D. Kandou Manado, $67.5 \%$ pasien pascastroke iskemik mengalami gangguan kognitif. Di Rumah sakit Dr Jamil dan Rumah Sakit Islam Ibnu Sina Padang, angkanya mencapai sekitar 20- 50\%. ${ }^{5}$ Penulis mengadakan studi untuk meneliti hal tersebut karena data valid di Rumah Sakit Umum Pusat Sanglah belum tersedia.

\section{METODE}

Jenis penelitian yang digunakan adalah penelitian deskriptif cross-sectional dengan desain studi

\section{Tabel 1 Karakteristik Sampel Penelitian}

\begin{tabular}{lc}
\hline Karakteristik & $\mathbf{n = 2 6}$ \\
\hline Usia (Tahun) (n,\%) & $3(11,5 \%)$ \\
21 - 30 & $6(23 \%)$ \\
31 - 40 & $10(38,5 \%)$ \\
$41-50$ & $7(27 \%)$ \\
51 - 60 & \\
Jenis Kelamin (n,\%) & $18(69,2 \%)$ \\
Laki - laki & $8(30,8 \%)$ \\
Perempuan & \\
Tingkat Pendidikan (n,\%) & $5(19,2 \%)$ \\
Tidak Sekolah & $2(7,6 \%)$ \\
Sekolah Dasar (SD) & $7(27 \%)$ \\
Sekolah Menengah Pertama (SMP) & $8(30,8 \%)$ \\
Sekolah Menengah Atas (SMA) & $4(15,4 \%)$ \\
Sarjana (S1) & \\
Fungsi Kognitif (n,\%) & $21(80,8 \%)$ \\
Terganggu & $5(19,2 \%)$ \\
Normal &
\end{tabular}

kuantitatif, dimana peneliti melakukan pengumpulan data dengan menggunakan pengisian kuesioner dan tes Montreal Cognitive Assesment versi Indonesia (MoCA-Ina). Penelitian ini dilakukan selama empat bulan, yaitu dari bulan Oktober 2018 - Januari 2019 di Poliklinik Saraf RSUP Sanglah Denpasar. Populasi dalam penelitian ini adalah pasien dengan riwayat Stroke yang melakukan kontrol di Poliklinik Saraf RSUP Sanglah Denpasar. Kriteria inklusi dalam penelitian ini yaitu pasien dengan riwayat stroke iskemik, usia antara 30-65 tahun. Kriteria eksklusi pada penelitian ini adalah pasien dengan kondisi penyakit neurodegenerative seperti Dementia Alzheimer, Parkinson. Pencarian sampel dalam penelitian ini dilakukan secara konsekutif, dimana sampel yang memenuhi kriteria inklusi dan eksklusi langsung menjadi sampel dalam penelitian.

Penilaian fungsi kognitif menggunakan kuesioner Montreal Cognitive Assesment versi Indonesia (MoCA-Ina), kuesioner ini tersusun atas dimensi penilaian fungsi visuospasial/eksekutif, atensi, memori, atensi, bahasa, dan orientasi. Hasil dari penilaian fungsi kognitif dikelompokkan menjadi dikategorikan menjadi dua yaitu fungsi kognitif normal (skor $\geq 26$ ) dan gangguan fungsi kognitif (skor < 26). Dilakukan pencatatan terhadap karakteristik subjek seperti usia jenis kelamin, dan tingkat pendidikan. Analisis statistik dalam penelitian ini dilakukan menggunakan bantuan program SPSS versi 20.0, data ditampilkan dalam bentuk tabel.

\section{HASIL PENELITIAN}

Pada penelitian ini, jumlah sampel yang diperoleh sebanyak 39 pasien pasca stroke iskemik yang dipilih dengan teknik total sampling. Jumlah keseluruhan sampel yang memenuhi kriteria inklusi serta tidak memenuhi kriteria ekslusi diperoleh sejumlah 26 pasien selama periode November 2018 - Januari 2019.

Karakteristik usia menunjukkan lebih banyak sampel dengan usia 41-50 tahun (38,5\%), jenis kelamin laki-laki (69,2\%), tingkat pendidikan sekolah menengah atas $(30,8 \%)$, dan dengan fungsi kognitif yang terganggu $(80,8 \%)$.

Tabel 2, persentase terbesar pasien pasca stroke iskemik yang mengalami gangguan fungsi kognitif di RSUP Sanglah berada pada rentang usia 41-50 tahun dengan jumlah sebesar $34.6 \%$ serta diikuti oleh rentang usia 41-50 tahun, 31-40 tahun, dan 21-30 tahun berurutan dengan jumlah $27 \%$, $11.5 \%$, dan $7.7 \%$. Kemudian dari segi jenis kelamin laki-laki cenderung lebih banyak mengalami gangguan kognitif dibandingkan dengan perempuan (53,8\%). 
Tabel 2 Gambaran Fungsi Kognitif Berdasarkan Karakteristik Sampel Penelitian

\begin{tabular}{|c|c|c|c|}
\hline \multirow[b]{2}{*}{ Karakteristik } & \multicolumn{2}{|c|}{ Fungsi Kognitif } & \multirow[b]{2}{*}{ Total (\%) } \\
\hline & Terganggu (\%) & Normal (\%) & \\
\hline \multicolumn{4}{|l|}{ Usia } \\
\hline $21-30$ & $2(7,7)$ & $1(3,85)$ & $3(11.5)$ \\
\hline $31-40$ & $3(11,5)$ & $3(11,5)$ & $6(23)$ \\
\hline $41-50$ & $9(34,6)$ & $1(3,85)$ & $10(38.5)$ \\
\hline $51-60$ & $7(27)$ & $0(0)$ & $7(27)$ \\
\hline \multicolumn{4}{|l|}{ Jenis Kelamin } \\
\hline Laki - laki & $14(53,8)$ & $4(15,4)$ & $18(69.2)$ \\
\hline Perempuan & $7(27)$ & $1(3,8)$ & $8(30.8)$ \\
\hline \multicolumn{4}{|l|}{ Tingkat Pendidikan } \\
\hline Tidak Sekolah & $5(19,2)$ & $0(0)$ & $5(19.2)$ \\
\hline Sekolah Dasar (SD) & $1(3,8)$ & $1(3,8)$ & $2(7.6)$ \\
\hline Sekolah Menengah Pertama (SMP) & $7(27)$ & $0(0)$ & $7(27)$ \\
\hline Sekolah Menengah Atas (SMA) & $6(23,1)$ & $2(7,7)$ & $8(30.8)$ \\
\hline Sarjana (S1) & $2(7,7)$ & $2(7,7)$ & $4(15.4)$ \\
\hline \multicolumn{4}{|l|}{ Domain gangguan } \\
\hline Bahasa & $18(69,2)$ & $8(30,8)$ & $26(100)$ \\
\hline Atensi & $25(96,2)$ & $1(3,8)$ & $26(100)$ \\
\hline Memori & $26(100)$ & $0(0)$ & $26(100)$ \\
\hline Visuospasial & $7(27)$ & $19(73)$ & $26(100)$ \\
\hline Fungsi Eksekutif & $11(42,3)$ & $15(57,7)$ & $26(100)$ \\
\hline
\end{tabular}

Pada penelitian ini, pasien pasca stroke iskemik di RSUP Sanglah yang paling banyak mengalami gangguan fungsi kognitif mempunyai tingkat pendidikan Sekolah Menengah Pertama (SMP) dengan jumlah 7 pasien. Berdasarkan gangguan domain yang terjadi didapatkan jumlah dan persentase antara pasien yang domain kognitifnya terganggu atau tidak berdasarkan hasil tes MoCA-Ina, antara lain: bahasa $69,2 \%$, atensi $96,2 \%$, memori $100 \%$, visuospasial $27 \%$, dan fungsi eksekutif 42,3\% (Tabel 2).

\section{PEMBAHASAN}

Berdasarkan hasil penelitian, jumlah pasien pasca stroke iskemik di RSUP Sanglah yang mengalami penurunan fungsi kognitif lebih banyak daripada yang tidak dengan perbandingan 21:5. Hasil ini diperkuat oleh penelitian Trinita $\mathrm{dkk}^{5}$ di mana sebanyak 41 sampel pasien pasca stroke di RSUP Prof. Dr. R. D. Kandou di Manado, semua mengalami penurunan fungsi kognitif. Pada penelitian Muslamiyah Hanas dkk. ${ }^{6}$ persentase pasien yang mengalami gangguan fungsi kognitif pasca stroke mencapai $92.68 \%$. Banyaknya pasien pasca stroke iskemik yang mengalami gangguan kognitif disebabkan karena otak mengalami kekurangan suplai darah yang membawa oksigen dan nutrien-nutrien penting akibat dari penyumbatan pada pembuluh darah, sehingga terjadi hipoksia serebri dan degradasi fungsi bagian otak yang mengontrol kelima domain fungsi kognitif. ${ }^{7}$

Penelitian oleh Akmal dkk. ${ }^{8}$ pada tahun 2015 menyatakan bahwa probabilitas pasien pasca stroke mengalami gangguan fungsi kognitif mencapai angka 63\%, dengan kemungkinan lebih tinggi didapatkan pada pasien geriatri dan pendidikan rendah. Hasil ini didukung oleh penelitian Harada dkk. ${ }^{9}$ yang membahas tentang pengaruh normal aging terhadap fungsi kognitif, di mana fungsi kognitif mulai menurun secara normal dari usia 45 tahun. Hal ini disebabkan karena degradasi fungsi otak akibat efek penuaan terjadi secara berproses mulai dari ukuran, vaskularisasi, dan kognisi. Penurunan jumlah sel dan neuron pada otak menginisiasi gangguan atensi dan memori terlebih dahulu, serta dilanjutkan penurunan kemampuan vokal dan bahasa.

Adanya temuan mengenai stroke dan gangguan fungsi kognitif lebih banyak dialami ole lakilaki, hal ini terjadi karena neurosexism behavioral di mana kinerja fungsi otak laki-laki dan perempuan berbeda. Otak laki-laki mempunyai kemampuan visuospasial yang lebih baik, sedangkan otak perempuan mempunyai kemampuan atensi, verbal, dan memori jangka panjang yang lebih baik. Otak perempuan juga lebih bisa beradaptasi dengan konsep normal aging sehingga proses penurunan fungsi kognitif berjalan lebih lambat dari otak laki-laki. ${ }^{10}$

Penelitian oleh Muslamiyah Hanas dkk. ${ }^{7}$ tentang gambaran fungsi kognitif pasien pasca stroke, di mana pasien dengan lama pendidikan lebih dari 12 tahun lebih sedikit mengalami penurunan fungsi kognitif pasca stroke dibanding yang kurang dari 12 tahun. Hal ini disebabkan karena pada pasien yang berpendidikan lebih tinggi, fungsi otak lebih terlatih untuk berpikir, memperhatikan, dan menyimpan memori, sehingga fungsi kognitif dan psikologis lebih tinggi daripada pasien yang berpendidikan lebih rendah. Kemampuan untuk memecah masalah dan bertindak secara efektif pada umumnya didapatkan pada orang yang sudah mendapatkan pendidikan dan pengalaman pada bidang tertentu dalam jangka waktu yang lama. ${ }^{11}$

Domain yang paling terganggu adalah memori, lalu diikuti oleh atensi, bahasa, fungsi eksekutif, dan visuospasial. Pada penelitian oleh Harada dkk. ${ }^{9}$ fungsi memori dan atensi merupakan domain yang paling awal mengalami degradasi saat fungsi kognitif menurun. Kemampuan mengingat jangka pendek dan panjang berkurang seiring dengan 
kesulitan untuk berorientasi dengan keadaan sekitar, sehingga menyebabkan kebingungan pada pasien. Kemampuan vokal, verbal, dan pemahaman akan tutur kata mulai berkurang saat pasien mulai mengalami disorientasi dan penurunan atensi. Kemampuan menyelesaikan masalah, bertindak secara efektif, dan mempersepsikan bentuk ruang mulai berkurang seiring dengan bertambahnya usia. ${ }^{12,13}$

Keterbatasan dalam penelitian ini yaitu dilakukan di Poliklinik Saraf RSUP Sanglah Denpasar dengan menggunakan data primer berupa hasil kuesioner dan tes MoCA-Ina dalam kurun waktu 3 bulan. Pendeknya waktu penelitian menyebabkan sampel yang didapatkan kurang banyak. Sampel penelitian yang terbatas pada pasien yang pernah rawat jalan di poli saraf saja juga menyebabkan jumlah data inklusi kurang mencukupi. Kondisi poli saraf yang terkadang ramai membatasi waktu wawancara dan dikhawatirkan mempengaruhi hasil tes MoCA-Ina. Saat waktu penelitian, banyak juga pasien yang tidak memenuhi syarat untuk diuji MoCA-Ina karena buta huruf sehingga jumlah sampel yang drop out cukup banyak

\section{SIMPULAN}

Mayoritas pasien pasca stroke iskemik di RSUP Sanglah Denpasar mengalami gangguan fungsi kognitif dengan jumlah 21 dari total 26 pasien, berada pada rentang usia 41-50 tahun, berjenis kelamin laki-laki, mempunyai tingkat pendidikan Sekolah Menengah Pertama (SMP). Domain Kognitif yang paling terganggu pasca stroke iskemik adalah domain memori dan yang paling sedikit terganggu adalah visuospasial.

\section{KONFLIK KEPENTINGAN}

Penulis menyatakan tidak terdapat konflik kepentingan terkait publikasi dari artikel ini

\section{PENDANAAN}

Penelitian ini tidak mendapatkan pendanaan dari pemerintah ataupun sector swasta lainnya.

\section{ETIKA DALAM PENELITIAN}

Penelitian ini telah mendapatkan persetujuan dari Komite Etik Fakultas Kedokteran Universitas Udayana dengan nomer referensi 2250/UN 14.2.2.VII.14/LP/2018.

\section{DAFTAR PUSTAKA}

1. Kanyal N. The Science of Ischemic Stroke: Pathophysiology \& Pharmacological Treatment. International Journal of Pharma Research \& Review. 2015;4(10):65-84.

2. Bhatti AB, Ali F, Satti SA. Association Of Obesity With Stroke. International journal of Biomedical Research. 2013;4(8):422-426.

3. Medalia A, Revheim N. Dealing with Cognitive Dysfunction Associated with Psyciathric Disabilities [Internet]. The New York State Office of Mental Health Family Liaison Bureau; 2012 [Diakses 10 Januari 2018]. Tersedia di: http://www.omh.state.ny.us/omhweb/ resources.

4. Millan MJ, Agid Y, Brune M, Bullmore ET. Cognitive Dysfunction in Psychiatric Disorders: Characteristics, Causes and the Quest for Improved Therapy. Institut de Recherche Servier. 2012;11:141-168.

5. Trinita C, Mahama CN, Tumewah R. Penurunan Fungsi Kognitif Pada Pasien Stroke Di Poliklinik Neurologi Blu Rsup Prof. Dr. R. D. Kandou Manado Periode Oktober Desember 2013. Jurnal e-CliniC (eCl). 2014;2(2):17-22.

6. Hasra IW, Munayang H, Kandou LFJ. Prevalensi Gangguan Fungsi Kognitif dan Depresi Pada Pasien Stroke di Irina F RSUP Prof. DR. R. D. Kandou Manado [Skripsi]. Manado: Universitas Sam Ratulangi; 2014.

7. Hanas M, Lestari E, Asni EK. Gambaran Fungsi Kognitif Pada Pasien Pasca Stroke di Poliklinik Saraf RSUD Arifin Achmad Provinsi Riau. JOM FK. 2016;3(1):12-18.

8. Akmal, Irsyadi I. Faktor-faktor yang Memengaruhi Gangguan Fungsi Kognitif pada Pasien Pasca Stroke Iskemik [Thesis]. Padang: Universitas Andalas; 2015.

9. Harada CN, Natelson L, Marissa C, Triebel K. Normal Cognitive Aging. Clin Geriatr Med. 2013;29(4):737-752.

10. Goldman B. The Cognitive Differences Between Men and Women [Internet]. Standord Education; 2017 [Diakeses 18 Januari 2019]. Tersedia di: https://stanmed.stanford. edu/2017spring.

11. Guy R, Byrne B. Neuroscience and Learning: Implication for Teaching Practice. J Exp Neurosci. 2013;7:39-42.

12. Howieson DB. 2015. Cognitive Skills and the Aging Brain: What to Expect. Cerebrum. 2015; cer-14-15.

13. Hakimi R, Hakimi E. Rumi's cognitive therapy approach to health and disease. Bali Medical Journal. 2018;7(1):39-46. DOI:10.15562/bmj.v7i1.426

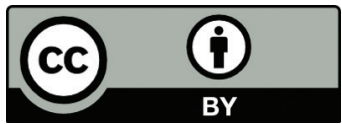

This work is licensed under a Creative Commons Attribution 